ORIGINAL ARTICLE

\title{
Complications Associated to High TIMI Score in Patients with Acute ST Elevation Myocardial Infarction
}

\author{
MAHBOOB UR REHMAN ${ }^{1}$, FARHAN FAISAL ${ }^{2}$, AMJAD ABRAR $^{3}$, AMJAD ALI SHAH $^{4}$, MUHAMMAD SHOAIB $^{5}$, MALIK ALI \\ RAZA 6 \\ ${ }_{1,2}$ Assistant Professor, Cardiac Centre Pakistan Institute of Medical Sciences, Islamabad \\ ${ }^{3}$ Associate Professor, Cardiology department, Gomal Medical College Dera Ismail Khan \\ ${ }^{4}$ Senior Medical officer, Cardiology Department, Saidu Teaching Hospital, Swat \\ ${ }^{5,6}$ Registrar Cardiology Pakistan Institute of Medical Sciences, Islamabad \\ Corresponding author: Dr Mahboob ur Rehman, Email Address: drmehboobfcps@yahoo.com, Cell No. 03339229552.
}

\begin{abstract}
Objective: To determine the complications associated to High TIMI risk score among patients presented with acute ST elevation myocardial infarction.

Study Design: Cross sectional

Place \& Duration: Study was conducted at Cardiac Centre of Pakistan Institute of Medical Sciences (PIMS), Islamabadfor duration of 6 months from January to June, 2020.

Methods: Total 290 patients of both genders with ages 35 to 80 years presented with acute myocardial infarction were included in this study. Patients detailed medical history including age, sex and residence were recorded. Thrombolysis in Myocardial Infarction (TIMI) risk score was calculated for each patient. Follow up was taken during the hospital stay and after discharge. Complications were recorded on follow-up. Data was analyzed by SPSS 21.0.

Results: From all the patients high TIMI score was found in $34.48 \%$ patients. Out of 100 patients $70 \%$ were male and $30 \%$ were females with mean age $54.25+12.65$ years. According to the high TIMI score $100(34.48 \%)$ patients had score above 8 and $190(65.52 \%)$ had score less than 8 . Complications were recorded ad Ventricular fibrillation, VT, AF, Heart block, cardiogenic shock and pulmonary edema in $17 \%, 13 \%, 2 \%, 7 \%, 24 \%$ and $24 \%$ patients respectively. $15 \%$ patients were died during hospital stay. $28 \%$ patients had post infarct angina, $9 \%$ patients had stroke and $28 \%$ patients treated revascularization.

Conclusion: We concluded from this study that frequency of high TIMI score is high in our setting and we patients with increase score had high risk of complications and mortality.

Keywords: High Thrombolysis in Myocardial Infarction, Acute ST Elevation Myocardial Infarction, Frequency, Complications, Mortality.
\end{abstract}

\section{INTRODUCTION}

Globally, ST elevation myocardial infarction (STEMI)is one of the most common life threatening malignant heart disorder with high rate of morbidity and mortality. In developing countries the incidence rate of myocardial infarction is high as compared to developed countries [1-2]. According to the previous studies conducted in Pakistan reported 1 out of 5 patients with ages 40 and above had coronary artery disease [3]. There is a high burden of heart diseases in developing countries and this contributes the high rate of mortality due to cardiovascular diseases.

In STEMI patients the most commonly risk is thrombolysis in myocardial infarction risk score [4-6]. TIMI risk score in STEMI patients is stratified as high risk score above 8 . The patients with TIMI score above 8 considered as high TIMI risk score and these patients have a high risk of morbidity and mortality [7-8]. Many of studies illustrated that the patients with high TIMI risk score above 8 had high rate of complications. Patients with ST-elevation acute myocardial infarction (STEMI), for whom early therapeutic options are welldefined, risk stratification has a great impact on late and early treatment modality decision making [9].

High TIMI risk score is directly associated to high rate of complications and deaths in patients with ST elevation myocardial infarction during hospital stay and at 1 year after high TIMI risk score evaluated. [10-11]. Present study was conducted aimed to examine the prevalence of High
TIMI risk score and complications associated to this malignant disorder in patients presented with acute ST elevation myocardial infarction.

\section{METHODS}

This study was conducted at Cardiac Centre Pakistan Institute of Medical Sciences (PIMS), Islamabadfor duration of 6 months from January to June, 2020. In this study total 290 patients of both genders with ages 35 to 80 years presented with acute myocardial infarction were included. Patients detailed medical history including age, sex and residence were recorded after taking written consent. Patients with history of previous myocardial infarction, patients with surgery of coronary artery bypass, patients with renal failure and not interested patients were excluded from study.

All the patients were clinically diagnosed to examine the frequency of high TIMI score. Complications were recorded during hospital stay till the discharge time. Mortality associated to high TIMI risk score was examined.

All the statistical data was analyzed by SPSS 21.0. Mean standard deviation was applied. Frequency and percentages were calculated to analyze the values.

\section{RESULTS}

From all the patients high TIMI score was found in $34.48 \%$ patients. Out of 100 patients $70 \%$ were male and $30 \%$ were females with mean age $54.25+12.65$ years. According to 
the high TIMI score 100 (34.48\%) patients had score above 8 and $190(65.52 \%)$ had score less than 8.

Table No 1. Frequency of high TIMI score among all patients

\begin{tabular}{|l|l|l|}
\hline TIMI Score & Frequency No. & Percentage \\
\hline$<8$ & 190 & 65.52 \\
\hline$>8$ & 100 & 34.48 \\
\hline
\end{tabular}

Out of all the patients who had high TIMI score we found ventricular fibrillation in 17 (17\%) patients, $13(13 \%)$ patients had VT, atrial fibrillation was found in $2(2 \%)$ patients, complete heart block was found in 7\% patients, 24 (24\%) patients had cardiogenic shock, pulmonary edema was found in 24 (24\%) patients, 28\% patients had post infarct angina, 9\% patients had stroke and $28 \%$ patients need revascularization.

Table 2: Complications recorded during hospital stay and at discharge and at $7^{\text {th }}$ day after discharge.

\begin{tabular}{|l|l|l|}
\hline TIMI Score & Frequency No. & Percentage \\
\hline Mean Age years & $54.25+12.65$ & \\
\hline Gender & 70 & 70 \\
\hline Male & 30 & 30 \\
\hline Female & \multicolumn{2}{|l|}{} \\
\hline Complications & 17 & 17 \\
\hline ventricular fibrillation & 13 & 13 \\
\hline VT & 2 & 2 \\
\hline atrial fibrillation & 7 & 7 \\
\hline complete heart block & 24 & 24 \\
\hline cardiogenic shock & 24 & 24 \\
\hline pulmonary edema & 28 & 28 \\
\hline post infarct angina & 9 & 9 \\
\hline stroke & 28 & 28 \\
\hline revascularization &
\end{tabular}

From all the patients $15(15 \%)$ patients were died during the hospital stay and in which 3 patients had TIMI score 9-10 and 12 patients had TIMI score 11-12. (Table 3)

Table No 3. Mortality associated to high TIMI score

\begin{tabular}{|l|l|l|}
\hline Characteristics & Frequency No. & Percentage \\
\hline Mortality & & \\
\hline Yes & 15 & 15 \\
\hline No & 85 & 85 \\
\hline Correlation with TIMI score & 3 & 3 \\
\hline 9 to 10 & 13 & 13 \\
\hline 11 to 12 & \multicolumn{2}{|l|}{} \\
\hline
\end{tabular}

\section{DISCUSSION}

Acute ST elevation myocardial infarction is one of the most common cardiovascular disease found all over the world [12]. In South Asian countries the frequency of high TIMI score in patients with acute myocardial infarction was high as illustrated in many previous studies and mortality rate is accounted 10 to $20 \%$ in those patients who had increase TIMI risk score [13-15]. Many of studies was conducted aimed to examine the frequency of high TIMI score in acute myocardial infarct patients. The present study was also conducted to examine the prevalence of high TIMI score in STEMI patients. In our study total 290 patients with ST elevation myocardial infarction were included to examine the high TIMI risk score. Out of 290 patients we found 100 $(34.48 \%)$ patients had TIMI score above 8 and 190 $(65.52 \%)$ patients had score less than 8 . These results were correlates to some previous studies in which the frequency of high TIMI score was reported 30 to $40 \%$ [1617].

In present study, from all the high TIMI score patients majority of patients were males $70 \%$ followed by females $30 \%$ with mean age $54.25+12.65$ years. A study conducted in Pakistan showed similarity regarding male patients' population in which male patients were high in number $64.5 \%$ as compared to females $31.84 \%$ with mean age $56.71 \pm 10.00$ years [18]. In our study we found ventricular fibrillation in 17 (17\%) patients, $13(13 \%)$ patients had VT, atrial fibrillation was found in $2(2 \%)$ patients, complete heart block was found in $7 \%$ patients. These results were comparable to some previous studies [19-20].

In this study 24 (24\%) patients had cardiogenic shock, pulmonary edema was found in 24 (24\%) patients, 28\% patients had post infarct angina, 9\% patients had stroke and $28 \%$ patients need revascularization. A study conducted by Kashif et al [18] reported $24 \%$ patients had cardiogenic shock, $27.3 \%$ patients had pulmonary edema and $24.8 \%$ patients need revascularization.

In present study, 15 (15\%) patients were died during the hospital stay and in which 3 patients had TIMI score 910 and 12 patients had TIMI score 11-12. We observed that the increase of TIMI score was highly correlates with morbidity and mortality. These results showed similarity to many other studies in which patients with high TIMI score found to had high rate of complications and mortality [2122].

\section{CONCLUSION}

Acute ST elevation myocardial infarction is most commonly found cardiovascular disorder. We concluded from this study that frequency of high TIMI score is high in our setting and we patients with increase score had high risk of complications and mortality.

\section{REFERENCES}

1. S Russo CA, Andrews RM. The National Hospital Bill: the most expensive condition by Payer.JAMA 2006;4:18-25.

2. Joshi $P$, Islam $S$, Pais P. Risk factors for early myocardial infarction in South Asians compared with individuals in other countries. JAMA 2007;297:286-94.

3. Jafar $\mathrm{TH}$, Jafary FH, Jessani S, Chaturvedi N. Heart disease epidemic in Pakistan: women and men at equal risk. Am Heart J 2005;150(2):221-6

4. Masood A, Naqvi MA, Jafar SS, Mufti AA, Akram Z. InHospital outcome of acute myocardial infarction in correlation with 'thrombolysis in myocardial infarction' risk score. J Ayub Med Coll Abbottabad 2009;21(4):24-7.

5. Rott D, Leibowitz D, Schwartz R, Weiss AT, Behar S, HodH.Combination of the Killip and TIMI classifications for early risk stratification of patients with acute ST elevation myocardial infarction.Cardiology 2010;117(4):291-5.

6. Truong Q, Cannon CP, Zakai NA, Rogers IS, Giugliano RP, Wiviott SD, et al.Thrombolysisinmyocardial infarction (TIMI) risk index predicts long-term mortality and heart failure in patients with ST-elevation myocardial infarction in the TIMI 2 clinical trial.Am Heart J 2009;157(4):673-9.

7. Lev El, Kornowski R, Vaknin-Assa H, Porter A, Teplitsky I, Ben-Dor I, et al. Comparison of the predictive value of four different risk scores for outcomes of patients with STelevation acute myocardial infarction undergoing primary percutaneous coronary intervention. Am J Cardiology 2008;102:6-11. 
8. Golabchi A, Sadeghi M, SaneiH,Akhbari MR, SeiedhosseiniSM,Khosravi $P$, et al.Can TIMI risk score predict angiographic involvement in patients with STelevation myocardial infarction. ARYA Atheroscler2010;6(2):69-73.

9. KozieradzkaA,KamińskiK,DobrzyckiS,Nowak K, Musial W.TIMI risk score accurately predicts risk of death in 30- day and one-year follow-up in STEMI patients treated with primary percutaneous coronary interventions. Kardiol Pol 2007;65(7):788-95.

10. Gale CP,Manda SO, BatinPD,BirkheadJ,HallAS.Validity of the TIMI risk scores for UA/NSTEMI and STEMI. Circulation 2006;114(Suppl 18):829.

11. Herrmann HC1, Lu J, Brodie BR, Armstrong PW, Montalescot G, Betriu A, Neuman FJ, et al. Benefit of facilitated percutaneous coronary intervention in high-risk ST-segment elevation myocardial infarction patients presenting to nonpercutaneous coronary intervention hospitals. JACC Cardiovaclnterv2009;2(10);917-24.

12. Ishaq M, Beg MS, Ansari SA, Hakeem A, Ali S. Coronary artery disease risk profiles at a specialized tertiary care centre in Pakistan. Pakistan J Cardiol2003;14:61-8.

13. Ghaffar A, Reddy KS, Singhi $M$. Burden of noncommunicable diseases in South Asia. BMJ 2004;328:811-5.

14. Di Bella G, Aquaro GD, Strata E, Deiana M, De Marchi D, Lombardi M, et al. Simultaneous visualization of myocardial scar, no-reflow phenomenon, ventricular and atrial thrombi by cardiac magnetic resonance. Int J Cardiol 2007;115:10-1.

15. Zapata G. Prediccióntempranadelriesgoen el Infartoagudo de miocardio: unadifíciltarea de todos los días. Rev Fed ArgCardiol2011;40:1-2.

16. Santos ES, Aguiar Filho Lde F, Fonseca DM, Londero HJ, Xavier RM, Pereira MP, et al. Correlation of risk scores with coronary anatomy in non-ST-elevation acute coronary syndrome. Arq Bras Cardiol2013;100:511-7.

17. Bawamia B, Mehran R, Qiu W, Kunadian V. Risk scores in acute coronary syndrome and percutaneous coronary intervention: A review. Am Heart J 2013;165:441-50.

18. Iltaf K, Dar MH, Khan I, Ali U, Hafizullah, Shah S. Frequency of high timi score and its short term clinical outcomes. Pak Heart J 2019; 52 (01):80-4.

19. Pedersen $\mathrm{F}$, Butrymovich $\mathrm{V}$, Kelbæk $\mathrm{H}$, et al. Short- and long-term cause of death in patients treated with primary $\mathrm{PCl}$ for STEMI. J. Am. Coll. Cardiol. 2014;64(20):2101-2108.

20. Kytö V, Sipilä J, Rautava P. Gender and in-hospital mortality of ST-segment elevation myocardial infarction (from a multihospital nationwide registry study of 31,689 patients) Am. J. Cardiol.2015;115(3):303-306.

21. González-Pacheco H, Arias-Mendoza A, Álvarez- Sangabriel A, Juárez-Herrera Ú, Damas F, Eid-Lidt G, et al. The TIMI risk score for STEMI predicts in-hospital mortality and adverse events in patients without cardiogenic shock undergoing primary angioplasty. Arch CardiolMex 2012;82(1):7-13. 